\title{
COMUNIDADE DE PRÁTICA ON-LINE: UMA ESTRATÉGIA PARA O DESENVOLVIMENTO PROFISSIONAL DOS PROFESSORES DE HISTÓRIA
}

Andréia de Assis Ferreira* Bento Duarte da Silva**

RESUMO: Este artigo discute o conceito de comunidades de prática on-line (CoP). Seu propósito é descrever e analisar a formação e consolidação de uma CoP composta por professores de História da Rede Municipal de Ensino de Belo Horizonte, bem como as potencialidades desse contexto no desenvolvimento profissional de professores. A metodologia usada foi a Netnografia. Foram identificados os elementos estruturais, estágio de desenvolvimento da comunidade e indicadores de eficiência. Essas informações permitiram traçar o diagnóstico do grupo, evidenciando os aspectos que permitem caracterizar um grupo de professores como uma comunidade on-line de prática e o estágio de desenvolvimento da gestão dessa comunidade. Os resultados desta investigação evidenciam que a CoP pode ser, de fato, uma estratégia pedagógica apropriada para o desenvolvimento profissional de professores.

Palavras-chave: Comunidades On-line de Prática; Desenvolvimento Profissional de Professores; Tecnologias de Informação e Comunicação.

\footnotetext{
* Pós-doutora em Educação pela Faculdade de Educação (FaE) da Universidade Federal de Minas Gerais (UFMG); Professora da Rede Municipal de Ensino de Belo Horizonte. E-mail: andreia.assis.ferreira@gmail.com

* * Doutor em Educação pela Universidade do Minho/Portugal; Diretor do Departamento de Estudos Curriculares e Tecnologia Educativa do Instituto de Educação da Universidade do Minho/Portugal. E-mail: bento@ie.uminho.pt
} 
ONLINE COMMUNITY OF PRACTICE:

A STRATEGY FOR PROFESSIONAL DEVELOPMENT OF HISTORY TEACHERS

ABSTRACT: This article discusses the concept of Online Communities of Practice (CoP) and aims to demonstrate the formation and consolidation of a CoP composed of professors of History of RME/BH and its possibilities in the context of professional development of teachers. The methodology used was Netnography. We identified the structural elements, stage of development and community indicators. This has allowed tracing the diagnostic group, highlighting the aspects that make possible to characterize a group of teachers as an online community of practice and the stage of development of the management of this community. The results of this research show that the CoP may be, in fact, an appropriate pedagogical strategy for the professional development of teachers.

Keywords: Online Communities of Practice, Professional Development of Teachers; Information Technology and Communication

\section{Introdução}

As Tecnologias de Informação e Comunicação (TIC) estabelecem novos sistemas de relações sociais, organizacionais e escolares. Para Silva (2008), as TIC contribuem fortemente para condicionar e estruturar a ecologia comunicacional ${ }^{1}$ das sociedades. Cada época histórica - e cada tipo de sociedade - possui uma determinada ecologia comunicacional que lhe é devida e proporcionada pelo estado das suas TIC, reordenando, de um modo particular, as relações espaço-temporais, nas suas diversas escalas - local, regional, nacional e global - que o ser humano manteve e mantém com o mundo, e estimulando e provocando transformações em outros níveis do sistema sociocultural - educativo, econômico, político, social, religioso, cultural (SILVA; PEREIRA, 2012).

$\mathrm{Na}$ educação, as TIC modificam, assim, os ambientes e as formas habituais de nos relacionarmos com o ensino e a aprendizagem. Criam formas inovadoras de interagirmos uns com os outros e de acesso ao saber e de produção do conhecimento.

Vivemos num tempo muito marcado pela incerteza e insegurança, tempos líquidos como metaforicamente Bauman (2001, 2010) designa a sociedade moderna. Esse fenômeno não poupa a educação e a escola, como é demonstrado em vários estudos, como o de Hargreaves (2004), provocando preocupações e desafios aos professores. Nas condições atuais de trabalho, professores ficam com pouco tempo disponível para 
dedicar ao seu próprio desenvolvimento profissional ou ao debate coletivo sobre os problemas da educação. Acrescente-se, ainda, que há um conjunto de fatores, como releva Manuel Castells (2004), desde os laborais, familiares, urbanísticos e políticos, que favorecem a instalação, na nossa sociedade, de um modelo de sociabilidade caracterizado pelo individualismo. Contudo, nesse ambiente social, emerge também uma ecologia pluralista da comunicação (SANTAELLA, 2010), suportada pelas tecnologias digitais com características marcadas pela conectividade, mobilidade e ubiquidade, propícias ao estabelecimento de novas formas de sociabilidade (SILVA, 2008).

Nesse contexto, uma das mais relevantes contribuições da presente ecologia digital reside na possibilidade de se criarem comunidades on-line de aprendizagem. Essas comunidades facilitam a comunicação entre os participantes, tendo em vista um aprendizado colaborativo, em que cada ator educativo pode contribuir e é convidado a fazê-lo, para a potencialização do trabalho do outro e do seu próprio trabalho.

$\mathrm{Na}$ primeira parte deste artigo, apresentaremos as principais características dos conceitos de comunidade de prática, suas evoluções subsequentes para uma comunidade de prática on-line (CoP) e seu papel no desenvolvimento profissional de professores. Prosseguimos com a metodologia utilizada para a produção, análise e tratamento dos dados, seguindo-se a apresentação e a discussão dos principais resultados.

\section{Fundamentação da problemática em estudo}

\section{Desenvolvimento profissional de professores}

Em uma perspectiva socioconstrutivista, o desenvolvimento profissional dos professores pode ser definido como um processo de reestruturação e reelaboração das concepções, crenças, atitudes e comportamentos (PONTE, 2006; COSTA, 2004). Nesse sentido, o construto desenvolvimento profissional refere-se a um processo complexo, que envolve a formação inicial e continuada, as experiências como aluno e professor, e que pode ocorrer não apenas a partir de cursos, seminários e oficinas, mas também no dia a dia, no contato com colegas, pais e alunos, nas leituras e reflexões pessoais. Dessa forma, envolve a aprendizagem de 
novos conhecimentos e habilidades que, gradativamente, passam a refletir no discurso, nos saberes e na prática do professor.

Entendemos que o desenvolvimento profissional não ocorre mediante a aplicação de modelos e técnicas desvinculados de um referencial teórico e do contexto educacional em que o professor atua. Nesse sentido, o professor terá um papel permanentemente de aprendiz, um papel de agente ativo na escola, disposto a colaborar com os colegas, seja quanto à prática docente, seja em relação a problemas educacionais mais amplos.

Para Fullan e Hargreaves (1992), entender o desenvolvimento profissional dos professores é (re)conhecer pelo menos quatro aspectos básicos: a) os objetivos, as intenções e o papel que o professor se atribui; b) o professor como pessoa, seus valores e características individuais; c) o contexto real em que o professor trabalha; d) a cultura escolar presente no cotidiano do professor e seus colegas. Para esses autores, situações que favorecem o desenvolvimento profissional do professor, geralmente, procuram evitar modismos e implementações cegas de novas estratégias de ensino e visam a criar comunidades nas quais os professores possam discutir e desenvolver seus propósitos coletivamente, ao longo do tempo. Nelas, os professores têm a oportunidade de conhecer e refletir acerca dos pressupostos e crenças subjacentes às suas práticas.

O desenvolvimento profissional está, portanto, associado à ideia de que a capacitação do professor para o exercício da sua atividade profissional é um processo que envolve múltiplas etapas e que, em última análise, está sempre incompleto (PONTE, 1998). Aceitar o desenvolvimento profissional como equivalente à formação contínua seria muito restrito, pois a formação passaria a ser a única via para o desenvolvimento profissional (IMBERNÓN, 2002). Assim, é imprescindível destacar que o sentido do desenvolvimento profissional dos professores depende das suas vidas pessoais e profissionais e das políticas e contextos escolares nos quais se realiza a atividade docente (DAY, 2001). Sendo assim, cada vez mais, o desenvolvimento profissional dos professores é considerado como um processo alimentado, não apenas pela formação inicial e contínua, mas também pela interação entre pares e pela reflexão pessoal, pela interligação entre teoria e prática, pela aprendizagem em contextos formais e informais. As reflexões, trocas entre professores, alunos, administradores, pais e comunidade podem tornar o desenvolvimento profis- 
sional um processo efetivamente colaborativo e diário. Dessa forma, o desenvolvimento profissional docente conjectura duas dimensões intrínsecas: uma formação profissional constante, e as condições concretas em que o professor exerce a sua prática docente, bem como sua valorização profissional.

Neste artigo, adotaremos o construto desenvolvimento profissional de professores da disciplina História para fazer referência ao processo que envolve a aprendizagem de novos conhecimentos e habilidades que, processualmente, passam a se refletir no discurso, nos saberes e na prática do professor. Entendemos que o processo de desenvolver-se profissionalmente compreende duas vertentes: uma, de desenvolvimento pessoal; outra, de desenvolvimento de conhecimentos, atitudes, habilidades e competências específicas (OLIVEIRA, 1997). Esse processo é influenciado por fatores pessoais, motivacionais, sociais, cognitivos e afetivos. As características do indivíduo, sua personalidade, sua motivação para mudar, os estímulos ou pressões que sofre socialmente e sua própria cognição e afeto possuem importante impacto sobre o processo.

Reconhecemos o desenvolvimento profissional como um processo complexo, permeado por numerosos fatores - idiossincráticos, socioculturais, psicológicos, afetivos, cognitivos, difíceis de conhecer e influenciar. Entretanto, entendemos que, à medida que o professor amplia seus saberes e se depara com inúmeras possibilidades de desenvolver sua prática, ele mesmo se torna consciente e capaz de buscar as condições necessárias para desenvolver-se profissionalmente. Não basta oferecer cursos de formação, capacitações e oportunidades de aprendizagem ao professor de História. É também preciso estimulá-lo e ouvi-lo, reconhecendo suas necessidades e experiências, como ponto de partida para qualquer proposta de desenvolvimento profissional; é preciso, ainda, que ele se torne agente de sua própria aprendizagem e mudança.

\section{Comunidade de prática}

Atualmente, o construto comunidade de prática está sendo amplamente empregado. Entretanto, nem todos os grupos que se envolvem em uma temática que lhes é comum podem ser denominados de comunidade e nem todas as comunidades são comunidades de prática.

Uma Comunidade de Prática é concebida por Wenger (1998) como um grupo de indivíduos com distintos conhecimentos, habilidades e expe- 
riências, que participam de modo ativo em processos de colaboração, compartilhando conhecimentos, interesses, recursos, perspectivas, atividades e, sobretudo, práticas, para a produção de conhecimento tanto pessoal quanto coletivo. $\mathrm{O}$ conceito de comunidade de prática implica uma perspectiva da aprendizagem como atuação social, e não individual. Nessa perspectiva, compreendemos, como Toulmin (2001), que, para aprender, é necessário participar, envolvendo-se ativamente em processos sociais, construindo e reconstruindo uma identidade de pertencimento à comunidade.

Dessa ideia resulta que nem todo envolvimento/engajamento é participação. Por exemplo, podemos estar engajados na leitura de um livro sem que sejamos um participante, porque essa situação não envolve um reconhecimento humano mútuo.

De acordo com Wenger (2006), uma comunidade de prática apresenta três características imprescindíveis: o domínio, a comunidade e a prática. O domínio é o ponto (tema) de interesse compartilhado pelos membros, implica um compromisso por parte destes com o assunto a abordar, ou seja, uma comunidade de prática "não é meramente um clube de amigos ou uma rede de conexões entre pessoas", tem uma identidade que é definida por esse domínio de interesse compartilhado. O envolvimento dos membros nesse domínio leva à segunda característica - a comunidade - pois eles envolvem-se em atividades conjuntas, compartilham informação e ajudam-se mutuamente, ou seja, "constroem relações que possibilitam aprender uns com os outros". Por fim, a prática, pois os membros da comunidade são "praticantes", desenvolvem um repertório compartilhado de recursos: experiências, histórias, ferramentas, formas de abordar problemas recorrentes, rotinas, linguagens, símbolos, dentre outros - em uma prática compartilhada.

Dentro de uma comunidade de prática, podem ser localizados distintos níveis de participação, que variam de acordo com o engajamento de cada um de seus componentes. Para Wenger (1998), o aprendiz precisa desenvolver uma habilidade de se engajar com outros membros, estabelecer relacionamentos, compreender o empreendimento da comunidade, contribuir para seus propósitos e fazer uso do repertório da prática para nela se engajar. Isso caracteriza o processo de aquisição de conhecimento na prática e o desenvolvimento de ambos os conhecimentos individual e coletivo. 
De acordo com Wenger, McDermott e Snyder (2002), os níveis de participação são classificados em: central, ativo e periférico, como representado na Figura 1.

\section{FIGURA 1}

Níveis de participação em uma comunidade de prática

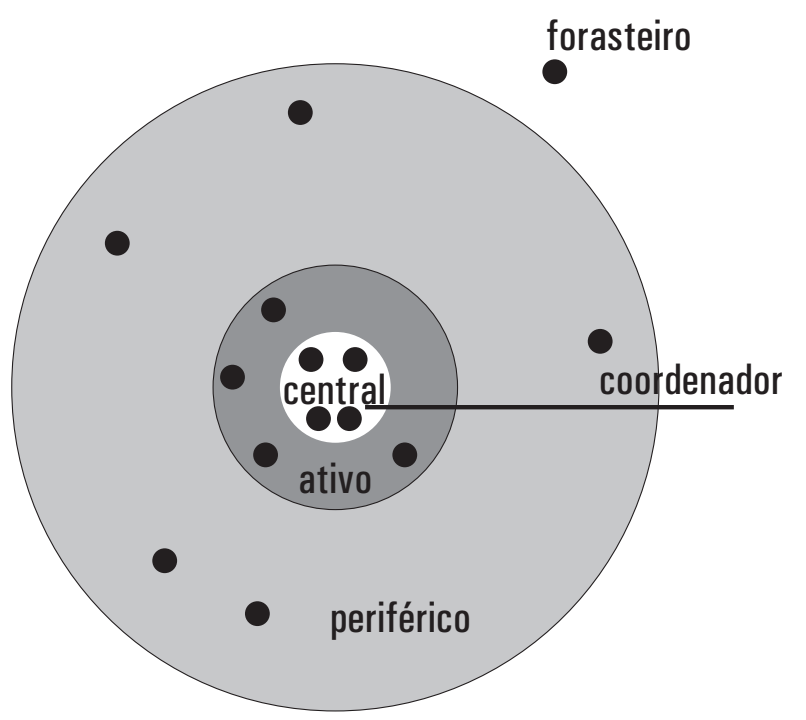

Fonte: Adaptado de WENGER; McDERMOTT; SNYDER, 2002, p.57.

No grupo central, encontra-se um pequeno número de membros cuja participação é muito ativa. Esse grupo é considerado o cerne da comunidade. Quando a comunidade alcança um nível de maturidade, os membros do núcleo tornam-se auxiliares do condutor da comunidade, desempenhando funções de mediadores, por exemplo, em um fórum de discussão. Os membros classificados no grupo ativo participam regularmente, mas sem a intensidade do grupo central. Já o nível periférico é onde grande parte dos componentes se encontra, conforme se percebe na figura. Seus componentes não participam dos debates diretamente, apenas acompanham as discussões realizadas pelos níveis central e ativo. É de se notar que membros de uma comunidade de prática transitam de um nível para o outro, essa movimentação pode acontecer quando os membros do nível periférico se movem para o centro motivados por um crescente senso de participação e pelo desejo de se tornar um participante pleno da prática. 


\section{Comunidade on-line de prática}

Quando a antropóloga Jean Lave, juntamente com Wenger, introduziu o conceito comunidade de prática, em 1991, não incluíam a possibilidade das comunidades de prática serem suportadas por tecnologias digitais. Contudo, os avanços tecnológicos proporcionaram o desenvolvimento das comunidades de prática on-line, isto é, grupos de professores que podem ficar juntos e fazerem uso das tecnologias de informação e comunicação aplicadas à educação para acessarem os recursos de ensino, compartilharem ideias e práticas pedagógicas inovadoras e refletirem sobre aspectos da prática de sala de aula (TREWERN; LAI, 2001).

O conceito de comunidade de prática implica relações de uma proximidade entre os membros, mas essa noção não se refere necessariamente ao contexto físico (geográfico) das tradicionais comunidades, pois o advento das tecnologias da informação e da comunicação, como a internet, possibilitou a multiplicidade de interações entre pessoas, independentemente de sua localidade geográfica. Organizadas virtualmente, elas se agrupam em torno de interesses e objetivos de natureza diversificada. Nesse sentido, Wenger (2006) considera que a web expande as possibilidades para a comunidade, mesmo para novos tipos de comunidades, com base na prática compartilhada.

Entendemos que uma comunidade de prática pode ser chamada de on-line ${ }^{2}$ quando os participantes, alinhados em torno de um interesse comum, comunicam-se, interagem e constroem conhecimento, de forma síncrona ou assíncrona, utilizando as tecnologias digitais de comunicação, nomeadamente as interfaces de comunicação da internet.

O construto 'Comunidade de Prática on-line' é uma tentativa de adaptação do conceito comunidade de prática para o espaço virtual. $\mathrm{Ou}$ seja, é uma rede colaborativa de indivíduos que partilham uma área de investigação e comunicam sobre ela, procurando ainda compreender os objetivos, estratégias, sentimentos, efeitos e contextos da aprendizagem que realizam, interagindo por meio dos recursos digitais de comunicação.

\section{Interface promotora de interação numa CoP: E-group}

A internet, enquanto meio de comunicação, apresenta distintas interfaces de comunicação que podem proporcionar uma maior integração, colaboração, cooperação e socialização de conhecimento e experiência entre os usuários. 
O termo 'ferramentas' tem sido amplamente utilizado no contexto da informática e da informática educacional para denominar qualquer recurso, instrumento que se usa para a realização de um trabalho, porém, como Levy (2001) e Santos (2006), optamos por nos referir aos dispositivos informáticos e multimídiacos como interfaces cognitivas. Para este autor, na relação homem-máquina, a fase da dificuldade da manipulação, da destreza técnica está ultrapassada devido à simplificação do hardware, dos programas, de modo que a relação do "homem" com o computador tem muito mais a ver com a vertente da informação e do conhecimento. Para Edméa Santos, "ganha o sentido de dispositivo para encontro de duas ou mais faces em atitude comunicacional, dialógica ou polifônica [...]. A interface está para a cibercultura como espaço on-line de encontro e de comunicação entre duas ou mais faces" (SANTOS, 2006, p.315).

Dentre as diversas interfaces da internet, as listas de discussão ou E-group passaram a existir ainda na década de 1970, como um dispositivo adaptado para a comunicação coletiva, fundamentado na cooperação dos participantes e no intercâmbio de conhecimentos. Os integrantes de listas de discussão não fazem uso apenas do correio eletrônico para enviar mensagens aos demais participantes do grupo, usam outros recursos e tecnologias que podem ser classificados como síncronos ou assíncronos.

$\mathrm{O}$ E-group tem-se tornado uma interface usual para suportar o compartilhamento de informações estruturadas entre membros de uma comunidade on-line. Nele, as pessoas se comunicam pela escrita, mas não necessariamente estando conectadas ao mesmo tempo (comunicação assíncrona). As mensagens vão sendo postadas e registradas numa tela que é acessada pelos participantes em diferentes momentos, ao contrário dos chats, por exemplo, em que a conversação é sincrônica.

Esse ambiente possui um desenho que favorece a participação ativa, ao possibilitar a publicação de conteúdo por qualquer dos participantes, ao permitir que o texto produzido e publicado possa apresentarse de forma mais elaborada, construído previamente, consequentemente, menos marcado pelo imediatismo da conversação no chat. O que é escrito e publicado, mesmo que possa ser modificado, não se perde como numa comunicação instantânea (sincrônica). Ao contrário, a produção do texto, de forma assíncrona, exige que ele fique registrado para que as pessoas possam acessá-lo em diferentes momentos, para responder ou dar 
continuidade à escrita. Isso viabiliza as consultas futuras, seja para simples retorno ao conteúdo, ou para análise do próprio processo, tanto pelos participantes quanto por pesquisadores que tenham acesso aos dados. Nesse sentido, o êxito de uma lista de discussão depende exclusivamente da participação dos membros para que seja vista como um lugar de intercâmbio coletivo, aberto a todos os interessados a compartilhar saberes, conhecimentos e desenvolver projetos em comum.

$\mathrm{Na}$ comunidade on-line investigada, o ambiente E-group foi a interface de comunicação assíncrona mais usada. ${ }^{3}$ Foi escolhido por ser, dentre os múltiplos ambientes existentes que podem consentir a colaboração, o que se apresentou mais facilmente aos usuários participantes da investigação, pois não necessita de programas especiais e aceita a participação assíncrona. Vários são os benefícios apresentados na participação em grupo de discussões em ambientes de comunicação mediada por computadores. Rojo (1995), Ferreira (2010) e Silva e Pereira (2012) evidenciam algumas vantagens: travar contato com ideias correntes, lançamentos e eventos no campo de estudo; ter a oportunidade de obter rapidamente respostas de qualidade; conseguir materiais de valor, ou indicações de como consegui-los; aprender sobre o meio em si; adquirir o sentimento de fazer parte de uma comunidade de interesse; ter a oportunidade de expressar ideias e sentimentos; ter a oportunidade de intensificar contatos com pessoas compartilhando interesses similares. No caso da comunicação assíncrona, o fato de os participantes terem mais tempo para refletir sobre suas questões, poderem pesquisar e responderem quando quiserem possibilita que as as suas postagens ${ }^{4}$ sejam mais ponderadas, acrescentando muito mais à discussão do que seria possível num ambiente presencial (ou on-line síncrono).

As listas de discussão existentes na internet possibilitam a socialização de informação e a produção coletiva do conhecimento, permitindo aos participantes analisar e discutir a perspectiva dos outros, refletirem sobre o seu próprio conhecimento e apresentarem seu ponto de vista. Assim, num tempo em que as circunstâncias não são muito propícias à sociabilidade baseada no lugar (escola), nossa hipótese é que essa interação on-line poderá constituir uma estratégia significativa para o desenvolvimento profissional dos professores. 


\section{Procedimentos metodológicos}

Considerando as questões iniciais propostas na investigação: "O grupo possui todos os elementos estruturais que o caracterizem como uma Comunidade de Prática on-line?"; "Baseado nos cinco estágios de desenvolvimento de Wenger (1998), em que estágio o grupo se encontra?"; "Como está o nível de participação de seus membros?", optamos por desenvolver uma investigação de cunho qualitativo, usando o método netnográfico.

A Netnografia, ${ }^{5}$ neologismo (nethnography $=$ net + ethnography) criado no final dos anos 90, surge para descrever o desafio metodológico de preservar os ricos detalhes da observação em campo etnográfico usando o meio eletrônico para seguir os atores (BRAGA, 2010).

É empregada como um recurso que auxilia na compreensão das estruturas socioculturais de apropriação das tecnologias de informação e comunicação por parte dos internautas, bem como da utilização dos instrumentos para criar novas relações sociais, discutir temas de interesse e com a possibilidade de estabelecer comunidades virtuais colaborativas.

Concordamos com Hine (2005) que as tecnologias de informação e comunicação ampliam a questão da multiplicidade metodológica, já que vão além da discussão sobre a evolução tecnológica em si, para as questões de sociabilidade e apropriação, uma vez que o agente de mudança não é a tecnologia em si, e sim os usos e as construções de sentido ao redor dela.

Essa escolha metodológica se justifica pelo fato de esse tipo de metodologia apresentar características condizentes com a natureza das questões que orientam este estudo. De acordo com Kozinets (2002), o método netnográfico foi elaborado especificamente com o intuito de adaptar as técnicas próprias ao método etnográfico (característico da antropologia) às necessidades relativas ao estudo das ciberculturas emergentes na sociedade em rede.

As técnicas de pesquisa etnográficas podem ser utilizadas também para o estudo das culturas e das comunidades agregadas via internet, sejam elas derivadas de grupos sociais já constituidos no off-line e que, nesse momento, migram e ou transitam entre esses espaços (como é o caso do grupo investigado) ou mesmo formações sociais compostas apenas por relações on-line (FRAGOSO et al., 2012, p.171). 
A pesquisa netnográfica é desenvolvida por meio da prática da observação participante, que resulta na coleta de dados por meio da observação junto ao grupo selecionado. Dá-se no/de e por meio do on-line e nunca está desvinculada do off-line, acontecendo através da imersão e engajamento intermitentes do pesquisador com o próprio meio (HINE, 2009). Nesse sentido, a observação participante não é, por si mesma, um método de pesquisa - ela é uma metodologia contextualizada e prevista pela Netnografia.

Ao contrário da etnografia tradicional, na qual o pesquisador se propõe a estudar a cultura de um grupo, observando gestos, atitudes do corpo e expressão facial (AGUIRREBAZTÁN, 1995), na Netnografia, outros elementos do ambiente virtual devem ser observados, como o layout das mensagens, o estilo do enunciado, a frequência das postagens dentre outros.

\section{Relação entre a pesquisadora e 0 grupo}

Embora tenhamos ${ }^{6}$ criado as condições iniciais necessárias para que os professores interessados em fazer parte do grupo se encontrassem off-line ou on-line, não houve de nossa parte a intenção de intervir e exercer o controle sobre o grupo.

A partir do primeiro encontro, todas as decisões, das mais simples (dia e periodicidade dos encontros, por exemplo) às mais complexas (como serão estruturadas as ações do grupo, por exemplo), foram decididas coletivamente. Dessa forma, fomos observadores participantes e compartilhamos entre os membros do grupo o papel de coordenação.

O processo vivido envolveu a constituição e a consolidação de um grupo colaborativo, que a presente pesquisa procurou decrever e analisar. Dessa forma, houve, por parte dos pesquisadores, tanto uma imersão ativa no processo construído e vivido pelo grupo quanto uma coleta contínua de dados através de variados instrumentos. 


\section{Questão ética}

Os professores são vistos, na presente pesquisa, como o centro do estudo, como sujeitos e não objetos de formação. Conhecer, respeitar e valorizar suas experiências e conhecimentos, aprender com eles e auxiliá-los em seu crescimento pessoal e profissional foram pontos básicos que nortearam nossas escolhas.

Cada professor assinou um Termo de Consentimento Livre e Esclarecido de acordo com as orientações do COEP/UFMG - Comitê de Ética em Pesquisa, aceitando participar da investigação.

Optamos, neste artigo, por usar nomes fictícios e sendo garantido ainda aos professores participantes o direito à leitura e aprovação prévia de todo material coletado, bem como das análises produzidas a partir deles.

Como Kozinets (2002), defendemos que o acesso aos dados por parte do grupo, além de eticamente recomendável, legitima e acrescenta credibilidade à pesquisa. Além disso, a participação do grupo amplia a compreensão do processo e pode levar a descobertas e conclusões que vão além das observadas em campo.

\section{0 grupo investigado}

Neste artigo, o foco principal das reflexões é o processo de constituição e consolidação de uma comunidade de prática on-line criada a partir da constituição de um grupo de trabalho colaborativo.

O grupo investigado formou-se em 2007 a partir do interesse por parte dos professores de História de uma escola municipal em discutir sobre as TIC no ensino de História, bem como do desejo da primeira autora deste artigo, de criar um grupo de trabalho colaborativo que refletisse acerca da mesma temática.

Atualmente, o grupo é composto por seis professores de História que atuam na Rede Municipal de Ensino de Belo Horizonte $\mathrm{RME} / \mathrm{BH}$, além da pesquisadora. Três deles atuam em uma mesma escola, e o restante em demais escolas da RME/BH. Todos os professores, em alguma medida, mostraram-se, desde o início da criação do grupo, engajados na busca de seu aperfeiçoamento profissional e acadêmico. 
Os participantes, desde 2007, reúnem-se mensalmente de forma presencial e on-line, por meio de uma lista de discussão do servidor Yahoo Grupos e pela rede social.

Nos encontros presenciais e on-line, foram realizadas reflexões acerca da prática dos professores participantes e de um domínio compartilhado de interesses (WENGER, 2006) como: tecnologias e educação, ensino de História, ensino de História e tecnologias de informação e comunicação aplicadas à educação, o uso de estratégias pedagógicas digitais no processo de ensino e aprendizagem, dentre outras temáticas que, por sua vez, se desdobraram em vários subtópicos suscitados pelas participações dos professores.

Para a coleta e análise dos dados, levaram-se em conta três tipos de captura de dados (KOZINETS, 2002). Na primeira, foram coletados os dados dos membros da comunidade, sendo que, devido ao grande número de informações recolhidas e às dúvidas que estas poderiam causar, foram utilizados vários tipos de filtros para que sobrassem apenas informações de relevância para o contorno da pesquisa. A segunda coleta referiu-se às informações obtidas a partir da observação das práticas comunicacionais dos membros da comunidade, das interações, simbologias e de sua própria participação. E, finalmente, na terceira, os dados foram levantados por meio da troca de e-mails e de um questionário ${ }^{7}$ elaborado e aplicado on-line.

\section{Resultados}

Identificamos, no processo de criação e consolidação da comunidade on-line investigada, as seguintes fases evolutivas: potencial, coalescente, em maturação e hospedagem (WENGER, 2002), como exemplifica a figura: 
FIGURA 2

Trajetória evolutiva da comunidade de prática on-line

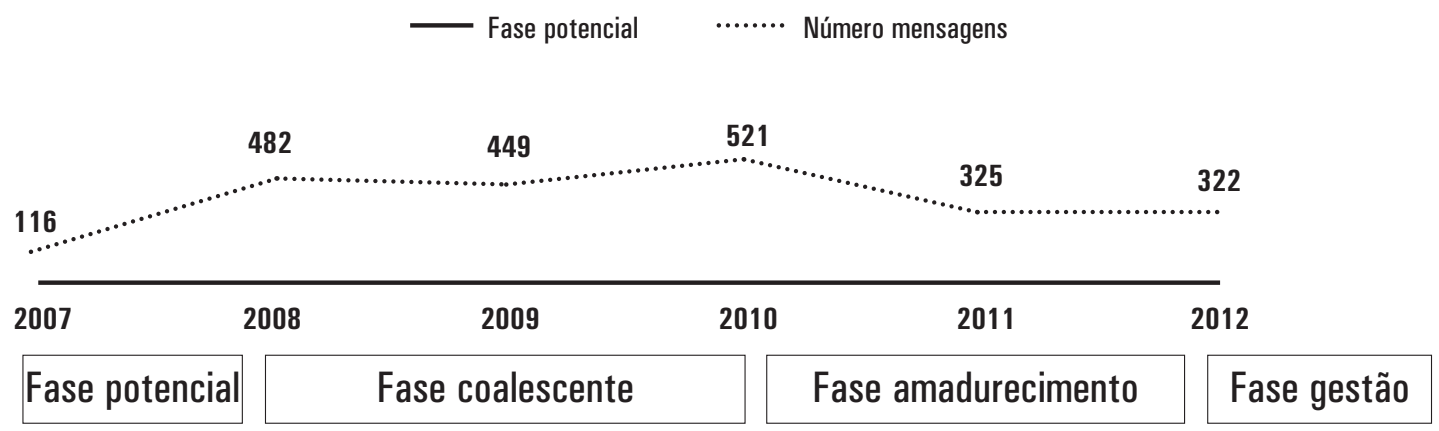

$\mathrm{Na}$ fase potencial, os professores descobriram um interesse em comum: ensino de História e TIC. Constataram que outras pessoas enfrentam problemas semelhantes, partilham uma paixão pelos mesmos assuntos e podem contribuir para novas aprendizagens. Foi definido que o grupo usaria a lista de discussão (E-group) como rede de partilha de informação, reflexão e produção coletiva de conhecimento.

À medida que os participantes foram construindo relações, confiança e consciência dos seus interesses e necessidades comuns, a CoP online evoluiu para a fase coalescente (WENGER, 2002). Os professores participantes descobriram o valor da partilha de informação acerca do domínio e da discussão de problemas da prática.

Assim, os professores, por meio da socialização de dicas, informações e experiências, conheceram intensamente a prática individual uns dos outros.

$\mathrm{Na}$ fase de amadurecimento, surgiu a necessidade de organizar, sistematizar e registrar o conhecimento produzido pela CoP. Nesses esforços, criaram-se padrões de boas práticas e identificaram-se temáticas a serem aprofundadas.

Um fato significativo observado, nessa fase, foi a demanda dos membros do grupo em desenvolver suas próprias pesquisas acadêmicas. Três professores ingressaram no mestrado em Educação e um ingressou em uma nova graduação (Filosofia).

De acordo com as fases da trajetória evolutiva da comunidade de prática on-line, descritas por Wenger (2002), a comunidade investigada se 
encontra atualmente na fase de gestão. Nessa fase, percebemos o desenvolvimento de um forte sentimento de orgulho no trabalho realizado, que origina um intenso sentimento de pertencimento. Os participantes sentem necessidade de socializar a experiência vivida e a sistematização dos conhecimentos produzidos, publicando artigos e participando de seminários e congressos acadêmicos. Esse sentimento de pertencer a uma comunidade eleva a satisfação e o comprometimento para a realização de esforços pelo grupo, bem como aumenta a colaboração entre as pessoas. É estabelecido, ainda, um movimento de 'tensão' entre a manutenção da posse do conhecimento construído e a abertura para novas ideias e membros.

\section{0 nível de participação de seus membros}

Em relação à participação dos membros, identificamos, ao longo dos cinco anos investigados, uma transição inicial do nível periférico para o nível ativo e uma transição mais atual do nível ativo para o nível central, como mostram as figuras:

\section{FIGURA 3}

Níveis de participação na comunidade de prática em 2007

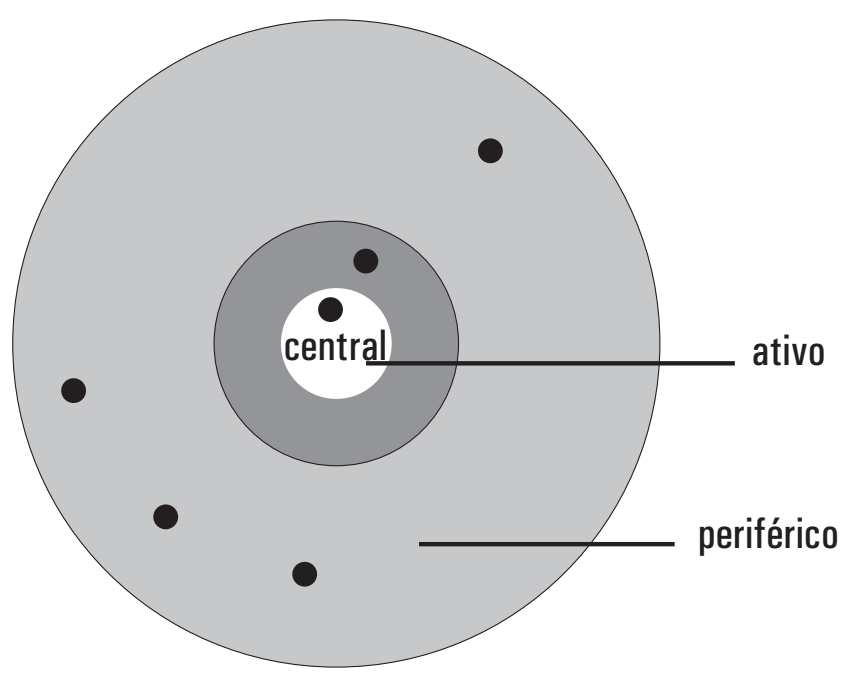




\section{FIGURA 4}

Níveis de participação na comunidade de prática em 2012

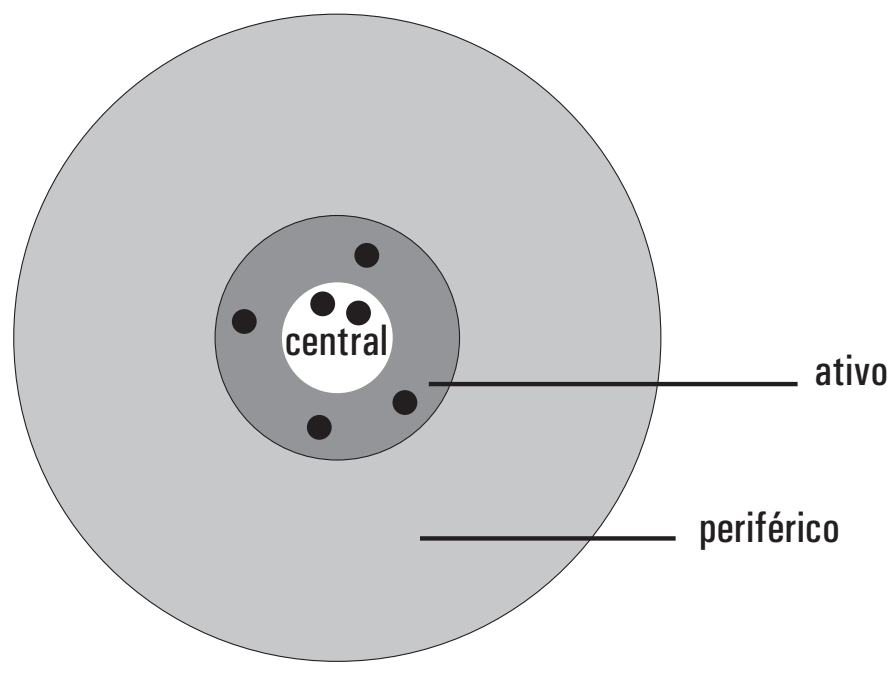

Pudemos registrar momentos de avanços e retrocessos, em circunstâncias diversas, evidenciados pelos próprios professores. Destacamos alguns:

No início, eu não achava que fazer parte desse grupo ia ser tão bom como é hoje. Eu tenho como característica participar ativamente de tudo que me comprometo, o que não significa que sempre tenho prazer nisso. Não é o caso do nosso grupo, que me provoca, me faz avançar profissionalmente, me coloca desafios bastante interessantes (Prof. 1).

Acho que depois de alguns encontros passei a falar muito mais. Acho que eu não deveria querer discutir tudo que aparece na roda (Prof. 2).

Sinto-me bem no grupo desde o início. Gosto de participar de grupos. À medida que fui conhecendo as pessoas, fui me abrindo, confiando nos colegas. Hoje, há mais confiança no grupo e nas pessoas (Prof. 3).

Acredito que nosso grupo se tornou uma comunidade de prática de acordo com o que estamos lendo sobre esta teoria. Ou melhor, penso que nos tornamos uma comunidade de sentidos (Prof. 3).

No decorrer dos anos, houve um crescimento exponencial na participação dos membros. O elevado grau de participação na comunidade e o modo como as interações têm ocorrido nos leva a assegurar que foram dados passos essenciais na direção de ultrapassar os papéis hierar- 
quizados, promovendo interações colaborativas nas quais todos possam se sentir mais confortáveis e seguros.

\section{Aspectos do grupo que o caracterizam como uma comunidade de prática}

Foram destacadas, no grupo, por meio da observação e das análises das discussões presenciais e on-line, as seguintes unidades de análise (WENGER, 1998), que permitiram identificá-lo como uma comunidade de prática:

1) Manutenção de relações mútuas (harmônicas ou conflituosas).

2) Modos compartilhados de engajamento/envolvimento em tarefas coletivas.

3) Fluxo rápido de informações e propagação de inovações.

4) Ausência de preâmbulos introdutórios (como se conversações e interações fossem meramente a continuação de processos em andamento).

5) Apresentação rápida de um problema a ser discutido.

6) Consenso substancial nas descrições dos participantes sobre quem pertence à

comunidade de prática.

7) Conhecimento sobre o que os participantes sabem, o que eles podem fazer, e como eles podem contribuir para um empreendimento.

8) Identidades sendo definidas mutuamente.

9) Habilidade de acessar e apropriar ações e produtos.

10) Instrumentos específicos, representações e outros artefatos.

11) Mitos locais, histórias compartilhadas, brincadeiras internas.

12) Jargões e modos rápidos e eficientes de comunicação, bem como facilidade de produzir novos jargões e modos de comunicação.

13) Certos estilos reconhecidos como associados aos membros.

14) Discurso compartilhado que reflete certas perspectivas sobre o mundo (WENGER, 1998, p.125-126).

O grupo experimentou, e ainda experimenta, um momento de aprendizagem com duplo sentido: compartilhamento de reflexões, concepções e conhecimentos, mas também de aprendizagem individual e social (interajuda dos membros da comunidade) ao nível da desenvoltura digital, ambientação no uso do E-group e da comunicação on-line, uma vez que os graus de imersão cibercultural eram distintos entre os membros. 


\section{Análise temática das mensagens}

Foram categorizadas 2.260 mensagens enviadas durante os cinco anos investigados (FERREIRA, 2010) nos seguintes blocos temáticos, referentes às aplicações que os professores fizeram da lista: desafios do ensino de História, reflexões conceituais, socialização de informação, compartilhamento da prática, produção coletiva de ações e práticas, mensagens que evidenciam aspectos do funcionamento da própria comunidade, dúvidas e preocupações acerca de suas experiências em sala de aula. A maioria das mensagens trata de reflexões de temas educacionais e de estratégias de ensino e outros recursos pedagógicos construídos dentro e fora da CoP. Essas mensagens constituem indícios da produção de um repertório compartilhado (WENGER, 2002) e práticas pela comunidade.

Os membros discutiram, com bastante profundidade - mensurada a partir dos conteúdos das mensagens, do número das mesmas trocadas no E-group e das observações feitas dos encontros presenciais múltiplos temas relacionados ao ensino de História, como: a organização dos currículos de História, o processo de produção de conceitos históricos; temas relacionados ao ensino de História e as TIC, como: o uso de ferramentas digitais como estratégias pedagógicas para o ensino de História, a integração das tecnologias no dia a dia escolar, as dificuldades e potencialidades do uso das TIC; e temas relacionados ao desenvolvimento profissional dos professores, como: a formação inicial e suas limitações, a produção de projetos de pesquisa situados em sala de aula, pelos próprios professores, em colaboração com os membros da CoP, a aprendizagem situada, a colaboração como estratégia para o desenvolvimento profissional, dentre outras.

Os professores participantes da CoP destacaram, em vários momentos de discussão, que as TIC potencializam práticas pedagógicas em rede, propiciando uma maior abertura ao currículo e também podem potencializar o papel de protagonista dos alunos no processo de ensino e aprendizagem de História.

O potencial renovador e transformador das TIC é valorizado, apontando-se diferentes níveis dessa contribuição (em nível do ensino e aprendizagem, avaliação, reconfiguração curricular, propostas pedagógicas, gestão institucional e parcerias com espaços e órgãos externos à escola). 


\section{Concepç̃̃es dos professores acerca da comunidade}

Os dados provenientes do questionário on-line aplicado em 2012 demonstram que:

- Todos os membros do grupo pesquisado identificam-no como uma comunidade on-line de prática.

- Todos entendem que a CoP investigada é uma ferramenta essencial para a formação contínua de seus membros e pode ser utilizada na formação contínua de profissionais da sua área.

- Os recursos digitais foram destacados como forma de suprir a carência $^{8}$ das reflexões na formação inicial docente.

- As trocas, as interações, a participação nas discussões, a oportunidade de formação profissional e a amizade foram os elementos destacados como essenciais para que os membros se sintam parte da CoP.

- $\mathrm{Na}$ fase atual, $60 \%$ dos membros se sentem muito confortáveis em usar a lista de discussão e $40 \%$ se sentem confortáveis.

- 20\% dos membros avaliam a sua participação nas discussões da CoP on-line como muito boa, $40 \%$ como boa e $40 \%$ como regular.

- Os membros destacaram como seus principais objetivos ao continuar integrando a CoP: discutir temas relevantes para sala de aula; aprender com a interação com os demais participantes e construir práticas coletivas para sala de aula, investindo nos registros dessas práticas, na avaliação das mesmas e no replanejamento, crescer com a experiência e ampliar as possibilidades de inter-relações entre os conceitos trabalhados.

- É consensual, entre os membros, que o E-group sobrevive e é eficaz como meio que possibilita interações, reflexões, coautoria e trabalho colaborativo.

- O envolvimento e/ou participação individual nas discussões do E-group foi destacado como um dos aspetos fundamentais, sem o qual não seria possível a criação e o funcionamento de uma real comunidade de prática on-line.

A importância do E-group na CoP, como estratégia comunicacional e pedagógica, é destacada pelos professores, como exemplificam os dois depoimentos a seguir: 
Como dissemos na última reunião, o grupo anda ligeiro no virtual. Muitas questões são resolvidas no E-group, algumas de ordem prática, como a que horas reunir, o que levar de lanche, qual é o roteiro da reunião, etc., outras de ordem conceitual como essa agora, ou sobre webquest ou sobre a prática pedagógica. Outro ponto positivo que vejo nas listas de discussão é o seu caráter democrático, pela oportunidade de todos se expressarem livremente e serem ouvidos pelos demais. Concordo com a Andréia quando ela diz que essa ferramenta foi essencial para a consolidação do nosso grupo, pois ela nos aproximou (Prof.1).

O grupo virtual possibilita reflexões mais profundas: há um tempo para planejar as respostas. Há um tempo para escrever e, novamente, refletir sobre o escrito. Esse tempo faz muita diferença no debate. Daí eu acreditar que há aprofundamento. Não estou querendo dizer com isso que esse debate é melhor do que o outro, o presencial. Mas é diferente. O outro debate também tem a sua importância: o olho no olho, as interações, as sensações, o corpo falando (e, às vezes, de modo antecipado). O grupo virtual nos possibilita entender bem uma das potencialidades da internet: a autoria. Quanto conhecimento já produzimos nesse grupo. Nós não vamos escrever um livro? O grupo virtual tem dado um caldo muito bom para pensarmos no livro. $\mathrm{O}$ grupo virtual é articulador. Essa perspectiva que o prof. 1 apontou: organiza o trabalho e nos articula no campo conceitual. Eu apontaria ainda uma terceira linha: ele me lembra do compromisso que assumi com todos vocês e me possibilita participar com o tempo que tenho (Prof. 2).

$\mathrm{Na}$ fase atual, os professores percebem alguns aspectos a serem aprimorados na comunidade de prática, como: a consolidação de uma dinâmica de registro das produções coletivas, o fechamento dos objetivos propostos pelo grupo ${ }^{9}$ e a ampliação do grupo.

\section{Elementos fundamentais da comunidade de prática investigada}

Comunidades de prática são estruturas sociais complexas e, como resultado, uma série de fatores pode contribuir potencialmente para o seu sucesso e para seu fracasso (WENGER, 2006).

$\mathrm{Na}$ observação e análise dos cinco anos de vivência da comunidade de prática, identificamos os seguintes fatores que potencialmente contribuíram para sua constituição e consolidação: 
- Colaboração: o aspecto colaborativo é um dos elementos principais em uma CoP, pois, mediante colaboração, os membros compartilham ideias e experiências em um intercâmbio intelectual no qual se desenvolve a inteligência coletiva no ciberespaço. Entendemos que a colaboração não surge instantaneamente em um grupo. Ela é construída gradualmente à medida que confiança, afetividade e respeito são construídos.

- Interação: para que os membros de uma CoP alcancem suas metas, é essencial que haja interação entre eles. A interação é a engrenagem que move uma comunidade e a torna uma instância dinâmica, na qual acontece o processo de produção coletiva do conhecimento.

- - Identificação: paixão para o domínio é fundamental. É necessário que haja uma identificação, em alguma medida, pela temática central.

Liderança: um fator-chave de sucesso é a dedicação e habilidade das pessoas que tomam a iniciativa de fomentar a comunidade. Muitas comunidades falham, não porque os membros perderam o interesse, mas simplesmente porque ninguém tem tempo e energia para cuidar da logística e manter o espaço para as reflexões e construções coletivas.

- Tempo: o tempo é um desafio para a maioria das comunidades, cujos membros têm de lidar com prioridades concorrentes. Teoricamente, o tempo dedicado à comunidade não deve ser um problema se o interesse existe, mas, na prática, continua a ser um desafio constante.

- O diálogo: foi por meio do diálogo que nos conhecemos e construímos uma relação de respeito, confiança e responsabilidade. Além disso, foi por meio dessas interações que trocamos e construímos saberes.

- O afeto, confiança: de modo natural, os professores da CoP desenvolveram uma sintonia e confiança mútuas que não seriam possíveis de prever ou preparar antecipadamente. Participam pessoas diferentes entre si, porém, com algumas características comuns. Todas são pessoas sensíveis, comprometidas com sua profissão e que buscam voluntariamente uma oportunidade de trabalhar junto. Cada professor, a seu modo, em sua escola e a partir de suas próprias experiências e modo de ver o ensino e aprendizagem de História e a tecnologia, ansiava por um espaço de troca, de livre expressão e de crescimento.

A partir da literatura e de nossa experiência, compreendemos que é essencial, na construção da comunidade de prática, seja ela on-line ou presencial, um compromisso de trabalho de todos os envolvidos no 
grupo, na qual todos os participantes possuem um objetivo em comum e interagem entre si, o que somente ocorre no momento em que se passa a perceber os benefícios mútuos da formação e consolidação de tal comunidade.

\section{Conclusão}

Compreendemos que, na comunidade on-line investigada, fomos capazes de experimentar, na prática, os três elementos nucleares para a constituição de uma comunidade de prática apresentados por Wenger (1998): 1) Engajamento/envolvimento mútuo (organizado em torno dos objetivos que a comunidade busca alcançar); 2) Um empreendimento conjunto (e, consequentemente, negociação mútua e responsabilidade da qual se deve prestar contas); 3) Um repertório compartilhado (rotinas, linguagens, símbolos, modos de fazer as coisas, dentre outros). O terceiro elemento nuclear descrito por Wenger (1998), um repertório compartilhado, foi por nós evidenciado como o pano de fundo que deu sustentação ao trabalho.

A análise dos resultados desta investigação permite considerar que os docentes participantes dessa comunidade de prática encaram o desafio de ensinar na "Escola da Era da Internet" (SILVA, 2008) e possuem o próprio senso de comunidade, na qual todos os membros investem e contribuem, com valores e projetos compartilhados.

O grupo aqui estudado não recebia qualquer tipo de suporte financeiro. Contudo, os participantes raramente faltavam aos encontros presenciais ou virtuais, e todos tinham propósitos claros. Mesmo pertencendo a contextos escolares diferentes, soubemos compatibilizar nossos papéis, expectativas e saberes, desenvolvendo formas significativas de interação, produção coletiva de conhecimento e liderança compartilhada.

Em um contexto de carga horária excessiva, isolamento na sua sala de aula, dificuldades de transição da formação para a prática, falta de espaço e oportunidade de reflexão entre os pares, poucas têm sido as oportunidades para os docentes aprimorarem seu desenvolvimento profissional (DAL-GARNO; COLGAN, 2007). Nossa investigação e literatura nos evidenciaram que a CoP pode ser, de fato, uma ferramenta valiosa para auxiliar a superação dessa situação, ao passo que proporciona um 
ambiente alternativo em que os professores podem refletir sobre conteúdos específicos, práticas didáticas, necessidades de formação etc., colocar suas próprias dúvidas e oferecer sugestões a outros pares, e, dessa maneira, reinventar coletivamente sua prática.

Acreditamos que construímos um novo sentido para o conceito de colaboração em nosso grupo, na medida em que o compreendemos como uma 'igualdade entre distintos'. Reconhecendo nossas diferenças e valorizando-as como fonte de aprendizagem para o grupo, passamos a respeitar o papel de cada 'colaborador' em seu ritmo, a seu modo e dentro de suas condições.

Em síntese, este artigo, dentro de suas limitações, procurou, mais que destacar a conhecida massificação e empobrecimento da escola pública e a cristalização das práticas de ensino dos professores, ressaltar a singularidade e a beleza aí existentes, através da história do grupo colaborativo de professores de História, de sua constituição à sua consolidação como uma comunidade de prática. Professores de escola pública, cada qual com uma experiência, uma história de vida e um jeito de ser peculiar. Porém, todos trazem consigo o compromisso com o seu trabalho, com o próprio crescimento enquanto pessoa e enquanto profissional, como marca comum. Todos trazem consigo a coragem de olhar adiante e desejar realizar mais que hoje realizam. Eles confirmam diariamente nossa esperança de que tanto o ensino e a aprendizagem nas escolas públicas, quanto o desenvolvimento profissional dos professores têm chance de serem alterados, melhorados, ressignificados pela inserção das tecnologias de informação e comunicação aplicadas à educação. 


\section{NOTAS}

1 Ecologia cognitiva é o espaço de agenciamentos, de interações concretizadas nas coletividades pensantes de homens, tecnologias e instituições. Ecologia digital é um tipo de ecologia cognitiva, que se sustenta nas tecnologias da informação (LÉVY, 1997).

2 Machado (2003) faz uma distinção entre os construtos "comunidades on-line" e "comunidades virtuais". Conforme a autora, as comunidades "on-line" referem-se às comunidades em que os participantes já se conhecem presencialmente e que empregam algumas interfaces digitais para se comunicar.

3 Utilizamos o serviço gratuito do portal Yahoo Grupos. O Yahoo Grupos é um serviço gratuito oferecido pelo site www.yahoo.com.br, que proporciona um espaço para os usuários compartilharem informações através da participação em um grupo de discussão, também chamado de lista de discussão. Trata-se, portanto, de uma interface de comunicação da internet que funciona também como um banco de informações. $O$ usuário, cadastrado no Yahoo Grupos, tem acesso instantâneo a arquivos de mensagens, fotos, agendas, enquetes e links.

4 O estrangeirismo postagem é muito usado para designar a publicação num blogue de um texto ou outro objeto de comunicação concebido em qualquer linguagem (áudio, vídeo, etc.). Por similitude, vamos usar esse termo para a publicação/edição dos textos nas listas de discussão (E-group).

5 Principais autores que empregam o termo: Kozinets (2010), Gebera (2008), Montardo (2006), Sá (2002), dentre outros.

6 Optamos pela expressão na primeira pessoa do plural para indicar não apenas a construção conjunta do artigo - e da investigação na qual o mesmo foi gerado - como também o fato de que esta construção em si raramente é uma empreitada individual.

7 Foi desenvolvido um questionário semiestruturado com perguntas abertas e fechadas por meio dos recursos do Google docs. Cada integrante do grupo recebeu por e-mail um convite para responder ao questionário. Os dados coletados foram tabulados automaticamente e enviados para os pesquisadores.

8 De acordo com Ferreira (2010), 75\% dos docentes da RME/BH acreditam que deveria haver, no espaço de trabalho dos docentes, ou seja, na escola, no horário de trabalho dos professores, um tempo destinado à formação contínua. Como isso não acontece, o uso do ambiente virtual, fora da rotina diária escolar, pode ser uma alternativa.

9 Por exemplo, a confecção de um Livro/Manual com propostas de atividades para os professores de História do Ensino Fundamental, que integrem o Ensino de História e as TIC. 


\section{REFERÊNCIAS}

ÁNGEL, A. B. Etnografia: metodología cualitativa em la investigación sociocultural. Barcelona: Marcombo, 1995.

BAUMAN, Z. Modernidade líquida. Rio de Janeiro: Jorge Zahar, 2001.

BAUMAN, Z. Vivemos tempos líquidos. Nada é para durar. ISTOÉ On-line Independente, de 24/09/2010. Disponível em: <http://www.istoe.com.br/assuntos/entrevista/detalhe/102755_vivemos + tempos + liquidos + nada + e + para + durar + ?pathImagens $=\&$ path $=$ \&actualArea=internalPage $>$. Acesso em: 01 jul. 2013.

BRAGA, Adriana. Interações digitais: usos sociais da internet em perspectiva etnográfica. 2010. Disponível em: <http://www.puc-rio.br/pibic/relatorio_resumo2010/relatorios/ccs/com/COM-Adriana\%20Braga.pdf>. Acesso em: 01 out. 2013.

CASTELLS, M. A galáxia internet, reflexões sobre internet, negócios e sociedade. Lisboa: Fundação Calouste Gulbenkian, 2004.

COSTA, G. M. O professor de matemática e as tecnologias de informação e comunicação: abrindo caminho para uma nova cultura profissional. 221f. 2004. Tese (Doutorado em Educação) - Faculdade de Educação, Universidade Estadual de Campinas, Campinas, 2004.

DALGARNO, N.; COLGAN, L. Supporting novice elementary mathematics teachers' induction in professional communities and providing innovative forms of pedagogical content knowledge development through information and communication technology. Teaching and Teacher Education, New York, v.23, n.7, p.1.0511.065, 2007.

DAY, C. Desenvolvimento profissional de professores. Porto: Porto Editora, 2001.

FERREIRA, A. de A. Desenvolvimento profissional de professores de História: estudo de caso de um grupo colaborativo mediado pelas tecnologias de informação e comunicação aplicadas à educação. 271f. 2010. Tese (Doutorado em Educação) - Faculdade de Educação, Universidade Federal de Minas Gerais, Belo Horizonte, 2010.

FRAGOSO, S.; RECUERO, R.; AMARAL, A. Métodos de pesquisa para internet. Porto Alegre: Sulina, 2012.

FULLAN, M.; HARGREAVES, A (Orgs.). Teacher development and educational change. Londres: The Falmer Press, 1992.

GEBERA, O. W. La netnografía: un método de investigación en internet. Revista Iberoamericana de Educación, n.47/2. 10 out. 2008. Disponível em:

<http://www.rieoei.org/deloslectores/2486Gebera.pdf>. Acesso em: 06 out. 2013. HARGREAVES, A. O ensino na sociedade do conbecimento: a educação na era da insegurança. Porto: Porto Editora, 2004.

HINE, C. Virtual methods: issues in social research on the internet. Oxford: Berg, 2005.

HINE, C. Virtual ethnography. London: Sage, 2009.

IMBERNÓN, F. Formação docente e profissional: formar-se para as mudanças e incertezas. São Paulo: Cortez, 2002.

KOZINETS, R. The field behind the screen: using netnography for marketing research in online communities. Journal of Marketing Research, New York, n.39, p.61-72., feb. 2002. KOZINETS, R. Netnography: doing ethnographic research on-line. Sage, 2010.

LAVE, J.; WENGER, E. Situated Learning: legitimate peripheral participation. New York: Cambridge University Press, 1991. 
LÉVY, P. A inteligência coletiva: para uma antropologia do cyberespaço. São Paulo: Loyola, 1997.

LÉVY, P. Cibercultura. Lisboa: Instituto Piaget, 2001.

MACHADO, M. J. A internet como um meio facilitador da formação de professores ao longo da vida. In: DIAS, P.; FREITAS, V. (Coords.). Actas da III Conferência de Tecnologias de Informação e Comunicaşão na Educação. Braga: Centro de Competência da Universidade de Minho, 2003. MONTARDO, S. P. A busca é a mensagem: links patrocinados e marketing de otimização de Busca (MOB). Razón Y Palabra, México, v.11, ago./sept. 2006. Proyecto Internet del ITESM. OLIVEIRA, L. A acção-investigação e o desenvolvimento profissional dos professores: um estudo no âmbito da formação contínua. In: SÁ-CHAVES, I. (Org.). Percursos de formaşão e desenvolvimento profissional. Portugal: Porto Editora, 1997.

PONTE, J. P. Da formação ao desenvolvimento profissional. In: ACTAS do Profmat 98. Lisboa: Associação dos Professores de Matemática, 1998. p.27-44.

PONTE, J. P. Mathematics teachers' knowledge and practices. In: GUTIERREZ, A.; BOERO, P. (Eds.). Handbook of reaserch on the psychology of mathematics education: Past, present and future. Rotterdham: Sense, 2006. p.461-494.

ROJO, A. Participation in scholarly electronic forums. Tese (Doutorado em Educação), University of Toronto, 1995. Disponível em:

<http://www.oise.on.ca/ arojo/tabcont.html>. Acesso em: 01 jan. 2013.

SÁ, S. P. Netnografias nas redes digitais. In: PRADO, J. L.Crítica das práticas midiáticas. São Paulo: Hacker, 2002.

SANTAELLA, L. A ecologia pluralista da comunicação: conectividade, mobilidade, ubiquidade. São Paulo: Paulus, 2010.

SANTOS, E. Educação on-line como campo de pesquisa-formação: potencialidades das interfaces digitais. In: SANTOS, E.; ALVES, L. Práticas pedagógicas e tecnologias digitais. Rio de Janeiro: E-papers, 2006.

SILVA, B. Tecnologias, ecologias da comunicação e contextos educacionais. In: MARTINS, M.; PINTO, M. (Orgs.). Comunicação e cidadania: Actas $5^{\circ}$ Congresso da Associação Portuguesa de Ciências da Comunicação. Braga: Centro de Estudos de Comunicação e Sociedade (Universidade do Minho), 2008. p.1908-1920. Disponível em:

<http://hdl.handle.net/1822/18157>. Acesso em: 01 jul. 2013.

SILVA, B.; PEREIRA, M. Reflexões sobre dinâmicas e conteúdos da cibercultura numa comunidade de prática educacional. In: SILVA, M. (Org.). Formação de professores para a docência on-line. São Paulo: Loyola, 2012. p.29-51.

TOULMIN, S. Os usos do argumento. São Paulo: Martins Fontes, 2001.

TREWERN, A.; LAI, K.-W. On-line learning: an alternative way of providing professional development for teachers. In: LAI, K.-W. (Ed.). E-Learning: teaching and professional development with the internet. Dunedin: The University of Otago Press, 2001. p.37-55.

WENGER, E. Communities of practice: learning, meaning and identity. Cambridge: Cambridge University Press, 1998.

WENGER, E.; McDERMOTT, R.; SNYDER, W. Cultivating communities of practice: a guide to managing knowledge. Boston: Harvard Business School Press, 2002.

WENGER, E. Communities of practice: a brief introduction. 2006. Disponível em: <http://www.ewenger.com/theory/index.htm>. Acesso em: 27 maio 2013. 
Recebido em: 02/07/2013

Aprovado em: 07/11/2013

Contato:

Centro Pedagógico

Escola de Educação Básica e Profissional da UFMG

Núcleo de História

Avenida Antônio Carlos, 6627

CEP 31270-901

Belo Horizonte | MG | Brasil 